\title{
The Latent Diffusion Network among National Parliaments in the Early Warning System of the European Union
}

\author{
THOMAS MALANG ${ }^{1}$ iD and PHILIP LEIFELD ${ }^{2}$ ip \\ ${ }^{1}$ Department of Politics and Public Administration, University of Konstanz, Konstanz ${ }^{2}$ Department of Government, University of Essex, \\ Colchester
}

\begin{abstract}
Since the Treaty of Lisbon, national parliamentary chambers in the European Union can issue reasoned opinions on legislative proposals by the European Commission. These individual reasoned opinions lead to a review if at least one third of all chambers raise such concerns. Hence, coordination among parliaments is key. Using advances in inferential network analysis, this article infers the underlying diffusion pathways among national parliaments through which chambers are related to each other in their decisions to raise subsidiarity concerns. The emerging diffusion network is characterised by a compartmentalization into communities of European Union budget net contributor and net recipient countries. This descriptive finding has implications for the institutional effectiveness and aspired democratic legitimacy of the Early Warning System. A multivariate statistical network analysis confirms that diffusion occurs among net recipient countries and that weak institutions follow the lead of strong institutions in the Early Warning System.
\end{abstract}

Keywords: early warning system; EWS; network analysis; diffusion; national parliaments

\section{Introduction}

Konstanzer Online-Publikations-System (KOPS) URL: http://nbn-resolving.de/urn:nbn:de:bsz:352-2-rpiz9kkkdu106

The Treaty of Lisbon introduced stronger regional and national institutions into the European polity in December 2009. One of these institutions is the Early Warning System (EWS), which gives national parliaments the opportunity to scrutinise, and raise subsidiarity concerns about, legislative proposals made by the European Commission. Through the EWS, national parliamentary chambers can achieve that the Commission has to review a legislative proposal if the parliaments reach a threshold of one third of all chambers voicing concerns. This process is called a yellow card. ${ }^{1}$ Although this mechanism is still rather a 'weak' instrument from an output-oriented perspective - because the Commission can ultimately keep the legislative proposal in its original form - it is one of the few innovative institutional arrangements to increase the democratic legitimacy of international and supranational organisations.

The main activity within the EWS - and the empirical basis of almost all previous studies - is the submission of a reasoned opinion by an individual national parliament. After an initial wave of conceptual research on the new powers and potentials of democratic legitimacy of national parliaments in the EU (Crum and Fossum, 2009;

[Correction added on 20 March 2021, after first online publication: Philip Leifeld was designated as co-corresponding author.]

\footnotetext{
${ }^{1}$ There is also an orange card if one half of all parliaments raises subsidiarity concerns. Although never realised so far, the Commission would be forced to review the proposal, and if it decides to maintain its proposal, the Commission must justify its decision to the EU Parliament and Council as to why the proposal complies with the principle of subsidiarity.
} 
Cooper, 2012), a first empirical wave of studies analysed the EWS as a tool in which national chambers issued their reasoned opinions independently of each other (Gattermann and Hefftler, 2015; Williams, 2016; Huysmans, 2018). A second wave of empirical studies now challenges the conceptual thought of independent chambers, which was so far a building block of the empirical results. Building on case study evidence from the previous yellow cards (Cooper, 2012; Pintz, 2015; Fromage and Kreilinger, 2017), these studies now start from the assumption of interdependent national parliaments that communicate, coordinate, and maybe influence each other in the process of raising subsidiarity concerns (Buzogány, 2013; Sprungk, 2013; Cooper, 2015; Pintz, 2015; Fromage and Kreilinger, 2017; Malang et al., 2019). Research has shown that the EWS can be characterised as a temporal network of interacting parliamentary chambers from the different Member States in order to explain submission behaviour: Chambers influence each other along partisan lines in order to coordinate around joint subsidiarity concerns as a form of collective action (Malang et al., 2019).

In the present contribution, we adopt a macro perspective and ask how the repeated (inter)action within the EWS creates a network of diffusion pathways among the national parliaments. We assume that a central feature of the EWS is the dynamic interdependence among national parliaments because they repeatedly face a common set of choices of importance to each other, namely whether to state a reasoned opinion or not on a legislative proposal. While one can easily observe the individual opinion submissions by national chambers, empirically identifying the emergent network of diffusion pathways - a concept of substantial theoretical interest and valuable for predicting future opinion behaviour - is a non-trivial and innovative contribution. We apply, for the first time in the study of the EWS, a general method for inferring a diffusion network connecting national parliaments based only on their publicly observable submission of reasoned opinions.

The stable diffusion network is the backbone of the ideological coordination and social influence documented in the literature on the EWS. Our article maps and explains this network. Moreover, we discuss how and why this network is crucial for understanding the diffusion process of reasoned opinion submissions. In other words, which parliaments influence which other parliaments in their decision to raise concerns on a proposal? What communities of parliaments exist in the European Union that exert influence on each other, and how are they structurally connected or divided? Who are the net distributors, or 'opinion leaders', in the diffusion network? And do the observed communities match any cleavage lines known to scholars of European Union politics?

The results speak to the burgeoning literature on parliaments as "networkers" by revealing the topology through which parliaments in the European Union are connected and exploring who learns from whom (Kinski, 2020). Our contribution also advances the literature on political and legislative networks (Victor et al., 2017) by analysing a supranational institution with recent methodological innovations in social network analysis.

\section{Theoretical Background: Diffusion Pathways}

The Early Warning System has upgraded the powers of national parliaments in the European Union since the Treaty of Lisbon: every legislative draft is sent by the Commission to all national parliaments for scrutiny. Each chamber can scrutinise the drafts for a violation of the subsidiarity principle and can formulate a reasoned opinion to signal their concerns. We call 
such an individual reasoned opinion simply 'opinion' or 'concern' throughout the paper. If a draft legislation is interpreted as a violation of the subsidiarity principle by at least one third of the votes of all chambers (19 votes) ${ }^{2}$ the European Commission must review the draft, it can, however, maintain the original version after review. All lower and upper chambers of all EU states can participate in the EWS. Each national parliamentary chamber has one vote in bicameral systems and two votes in a unicameral system, resulting in 56 votes in total. The parliaments have a short time span of eight weeks from the transmission by the Commission to the formulation of the reasoned opinion. If a chamber concludes that a given proposal violates the subsidiarity principle, it uploads the reasoned opinion on the EU interparliamentary exchange (IPEX) platform where all other chambers can see the concern. This implies that a chamber that formulates the concern can signal its interest as to which proposal they want to change or block and all other chambers receive this cue of which proposal might be worth scrutinising more closely.

Conceptual work has highlighted the new role of national parliaments as 'networkers' (Sprungk, 2013). This literature casts national parliaments as a 'virtual third chamber' in EU decision making (Cooper, 2012), which is characterised by a diffusion of activities, practices, and institutions (Buzogány, 2013; Senninger, 2020). Yet, the network character of national parliaments in the EU is empirically under-researched. Most empirical studies focus on single cases of yellow cards (Cooper, 2015; Pintz, 2015; Fromage and Kreilinger, 2017), activities of specific chambers, or on factors of chambers that increase their probability to issue opinions, without considering the activities of all other chambers (Gattermann and Hefftler, 2015; Williams, 2016). While some recent studies emphasise the collective nature of the EWS process and conceptualise either the national parliaments as a collective actor (Auel and Neuhold, 2017) or the EWS process as a collective action problem (Malang et al., 2019), no empirical study so far has analysed the interdependent activity by mapping who influences whom in this network of concern activities. Consequently, Huysmans (2018) concludes that there is a need for a systematic study of inter-parliamentary co-operation between national parliaments in the EU.

Right from the beginning of the EWS, the network character of the system became apparent. On the political and administrative level, several organisational and virtual platforms were established to foster coordination and cooperation among the parliaments. As Dias Pinheiro (2016) shows through the reconstruction of the development of forums, national parliaments do have a natural incentive to cooperate with peer chambers after Lisbon. Most importantly, the Conference of Parliamentary Committees for Union Affairs of Parliaments of the European Union (COSAC) intensified the exchange between national chambers by its meetings. On a virtual level, the IPEX platform was created for real-time monitoring and coordination of activities related to the EWS - including the posting of reasoned opinions and political dialogues (Goldoni, 2016).

The EWS provides an ideal environment for diffusion processes by encouraging parliaments to look at, or learn from, each other. The Member States share many similarities and dissimilarities, including spatial location, type of welfare state, public opinion toward the EU, shared history or language, and economic benefits from the EU, some of which we will consider below as explanations of the diffusion network. This means that Member States are connected in several ways, and as a key result, national parliaments in the EWS

${ }^{2}$ This threshold is lower for draft legislative acts related to justice, freedom and security - one quarter.

C 2021 The Authors. JCMS: Journal of Common Market Studies published by University Association for Contemporary European Studies and John Wiley \& Sons Ltd. 
might look at specific chambers when deciding if a given policy proposal is worth scrutinising. Hence, reasoned opinions might spread throughout the Member States. Two tasks result from this: (1) to focus on single-policy opinion episodes to examine the micro-level activities of national parliaments in coordinating and cooperating the EWS, and (2) to look for consistent patterns of opinion diffusion between Member States at the macro level by describing the general connectedness and presenting explanatory factors to predict interdependent behaviour.

While a wealth of excellent scholarship already exists on the single-policy approach, which focuses mostly on the 'most successful' cases (in terms of number of reasoned opinions), we want to examine the foundational question if diffusion structures exist in the EWS when we take into account the whole universe of policies.

To do so, we begin by adopting a very simple and general definition of diffusion. Specifically, diffusion occurs when one chamber's decision about whether to submit a reasoned opinion is potentially influenced by the choices made by other chambers (Simmons et al., 2006; Graham et al., 2013). Put another way, opinion submission can be interdependent, where a chamber observes what other chambers have done and conditions its own decision to formulate a subsidiarity concern on these observations.

In addition to characterising reasoned opinion diffusion in terms of interdependence, the definition emphasises diffusion as a process, as opposed to an outcome (Gilardi, 2012). Our research interest focuses on the interdependent process that is conducive to the spread of reasoned opinions, not the extent of convergence that can result from it. Hence, we are not so much interested in the yellow cards, which would be the focus of convergence research (Holzinger and Knill, 2005), but the observable sequence in the process of EWS activity. This procedural knowledge is, at a more fundamental level, linked to understanding and predicting the likelihood of an outcome (for example a yellow card) and the democratic quality of the EWS.

What are the persistent diffusion pathways in the EWS? In line with Walker (1969) in his pioneering study of policy diffusion, there are two primary pieces of information that need to be stitched together in order to conceptualise these pathways. We try to determine (1) if a group of parliaments exists that serves as 'opinion leaders' and (2) how reasoned opinions spread from these pioneering early submission chambers throughout the whole EWS. Persistent diffusion pathways are sequences of opinion submission in which the initiating chamber shows the same submission pattern as its following chambers more frequently than randomly expected. By extension, the latent network of opinion diffusion is set up by stable patterns of opinion leaders and chambers that raise their subsidiarity concerns with a higher likelihood after these opinion leaders.

\section{Conceptualising Opinion Cascades in the EWS}

How can we identify opinion leaders and stable diffusion patterns? As in other diffusion studies, we need two crucial pieces of information: Who did something with respect to a given policy/legislative proposal (Requirement 1), and at which point in time (Requirement 2)? Both pieces of information are available for the EWS and can be generated for every legislative proposal for the whole time period for every chamber.

We identified every reasoned opinion for every legislative proposal since the beginning of the process in the IPEX database. Overall, our study consists of all 484 reasoned 
opinions by individual chambers from January 2010 until April 2019 (the activity of a chamber on a proposal, as formulated in Requirement 1). We then hand-coded the deadline dates and subsidiary concern dates for each parliament and each legislative proposal (Requirement 2). More information about distributions and crucial cases can be found in Cooper (2018) and in Online Appendix 1.

We model parliamentary chambers as nodes in a directed network - the unobserved, or latent, diffusion network. There can only be a tie between two chambers if one chamber (the sender) submitted reasoned opinions before another chamber (the receiver) about the same legislative proposals. These ties - or diffusion pathways - are assumed as stable over time, like an institutional backbone that permits parliaments to coordinate around opinions. To the best of our knowledge, there is no reason to believe that this backbone changed fundamentally over the study period, apart from stochastic temporal fluctuation. The network is directed because the temporal data on the chambers' individual opinion activities permit inferring who raised concerns about a proposal first and who followed. The prediction of the unobserved diffusion network among parliaments is based on the observed temporal sequences of subsidiarity concerns by individual chambers. These sequences for each legislative proposal are called 'cascades' because the model assumes that opinion-relevant information for each legislative proposal spreads through the diffusion network over the respective eight-week period in which parliaments can raise subsidiarity concerns. As will be argued below, mere sequentiality of opinions in these cascades is insufficient for establishing diffusion; sequential opinions of any two chambers must be observed more often than chance would predict.

Figure 1 shows four selected cascades as an illustration. For example, proposal $\mathrm{COD} / 2016 / 0133$ is a regulation to manage migration. In this cascade, the Hungarian National Assembly posted its opinion that the regulation violates the subsidiarity principle

Figure 1: Four Examples of Opinion Cascades (out of a Total of 191 Cascades). '1' and '2' Indicate First and Second Chambers of a Bicameral System. [Colour figure can be viewed at wileyonlinelibrary.com]

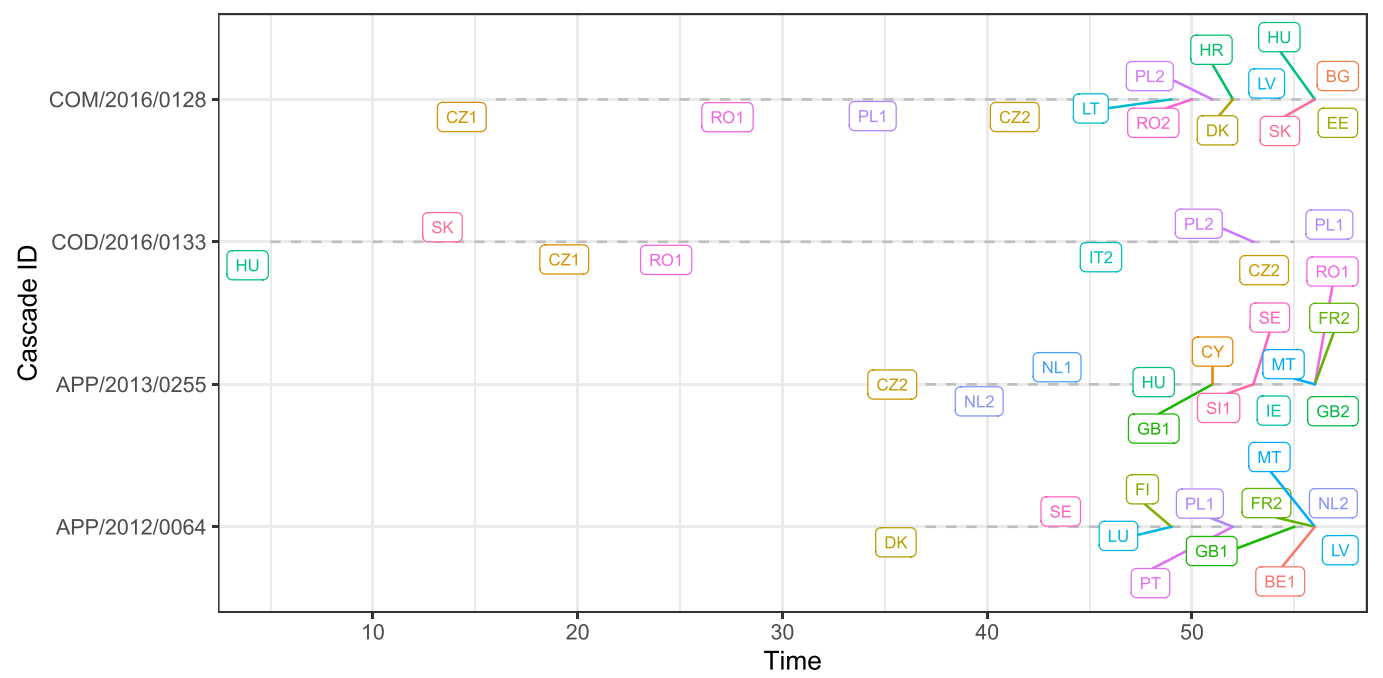


very early in the process, only a few days after the scrutiny process had begun. For Hungary, migration was a salient topic, which led to a high incentive to act as an influencer. The second chamber that submitted an opinion was the National Council of the Slovak Republic, on day 12 of the cascade around this proposal.

The literature on the EWS has provided case-based empirical evidence that earlier opinions influence later concerns by other chambers: In the case of the first yellow card, Monti II (APP/2012/0064 in Figure 1), Cooper (2015) demonstrates that the Danish Folketing played the role of an 'initiator', acting rapidly to adopt the first reasoned opinion, 'based on a conscious decision to try to persuade other national parliaments to do so with the expressed goal of achieving the first yellow card' (Cooper, 2015: 7). Within the cascade of the second yellow card - a regulation on the establishment of the European Public Prosecutor's Office (APP/2013/0255) - Pintz (2015: 99) concludes that the first opinions had a first-mover function and took on a leadership role in the process. This materialized in encouraging other parliaments to join the scrutiny process, providing substantive information, and monitoring the other parliaments regarding the vote count. Finally, in the process of the latest yellow card on the revision of the Posted Workers Directive (COM/2016/0128 in Figure 1), Fromage and Kreilinger (2017) attribute an agenda-setting function to the first chamber with an opinion, the Czech Chamber of Deputies, and conclude about the remaining opinions that 'it is most likely that coordination of some sort also took place among these national parliaments' (Fromage and Kreilinger, 2017, p. 145).

Apart from the evidence of the yellow card dynamics, we also find hints in the literature on how individual chambers actively try to use the EWS as a network. For the Dutch Tweede Kamer, qualitative evidence exists that they do not only use administrative and legislative networks to actively seek information on other parliaments' positions of given proposals, but that they also actively try to influence other parliaments through representatives of the Dutch Parliament in Brussels (Högenauer, 2015; Neuhold and Högenauer, 2016). Overall, there is consistent qualitative evidence in the literature that the EWS works on the basis of interdependent chambers that perceive and react to each other, which suggests the diffusion processes within the system should be investigated further.

Two concerns could be leveraged against the application of the diffusion concept to the EWS. First, one could argue that parliaments act completely independently without any reference to, and perception of, each other and hence the whole diffusion concept should not be applied to the EWS. However, the description of selected cases above already hinted towards coordinated activity of chambers within the EWS, and, furthermore, the whole setup of the institution and the common IPEX database seems to suggest an interdependent system of activity. As soon as a chamber starts scrutinising a subsidiarity concern, the obvious first activity would be to check if other chambers have already started the process. Efficiency (namely looking for templates or hints on which proposals might be worth scrutinising) as well as effectiveness (in terms of reaching a given threshold) suggest this reading of the process. Furthermore, there is existing quantitative evidence on patterns of influence between chambers in the EWS (Malang et al., 2019).

A second concern could be related to the temporal aspect of the EWS and the chambers acting in it. We stipulate in our study of diffusion that every subsequent submission is potentially influenced by previous opinions. This is a more conservative operationalisation of diffusion than found in other studies, which allow policy choices to be simultaneous or anticipatory, especially by introducing a strategic element into the interdependent choices 
(Franzese and Hays, 2006; Baybeck et al., 2011). In an extreme case, if two chambers submit opinions with a time lag of one day between the first and the second opinion in a potential diffusion dyad, the model assumes that the later chamber took the previous submission into consideration (though this may not be sufficient for inferring a diffusion tie if it happens rarely). Since parliaments are collective bodies and every decision takes a certain amount of time, it seems rather unlikely that a parliament is able to react within one day. Hence, the assumption to equate any temporal distance as a potential channel of influence could undermine our results. To substantiate our results, we will therefore provide complementary qualitative evidence and offer several descriptive insights about the temporal realisations on the level of the chamber, the cascades (the sequence of all opinions about one proposal), and ties (the inferred diffusion pathway between two chambers) below in the Results section. As a first reassurance, the aforementioned scenario with the one-day lag is rather uncommon. Of the 40 diffusion pathways that our analysis identifies, 15 ties have an average temporal distance that is smaller than seven days, and only two of the 40 pathways are built on an average duration smaller than three days.

Let us take a more systematic look at the activities of chambers in the EWS. Figure 2 plots the number of reasoned opinions per chamber on the $y$-axis (on a log scale). We can see that Sweden has the most active chamber when it comes to the submission of subsidiarity concerns. The Riksdagen formulated 85 reasoned opinions in the observed time period, followed by the second chambers of France (34 opinions) and Austria (30 opinions).

Beyond the sheer quantity of opinion submissions, the central component of our study is the pace of formulating them within the EWS. The $x$-axis of Figure 2 displays how

Figure 2: Scatterplot of Opinion Activity and Timing for Each Parliament. [Colour figure can be viewed at wileyonlinelibrary.com]

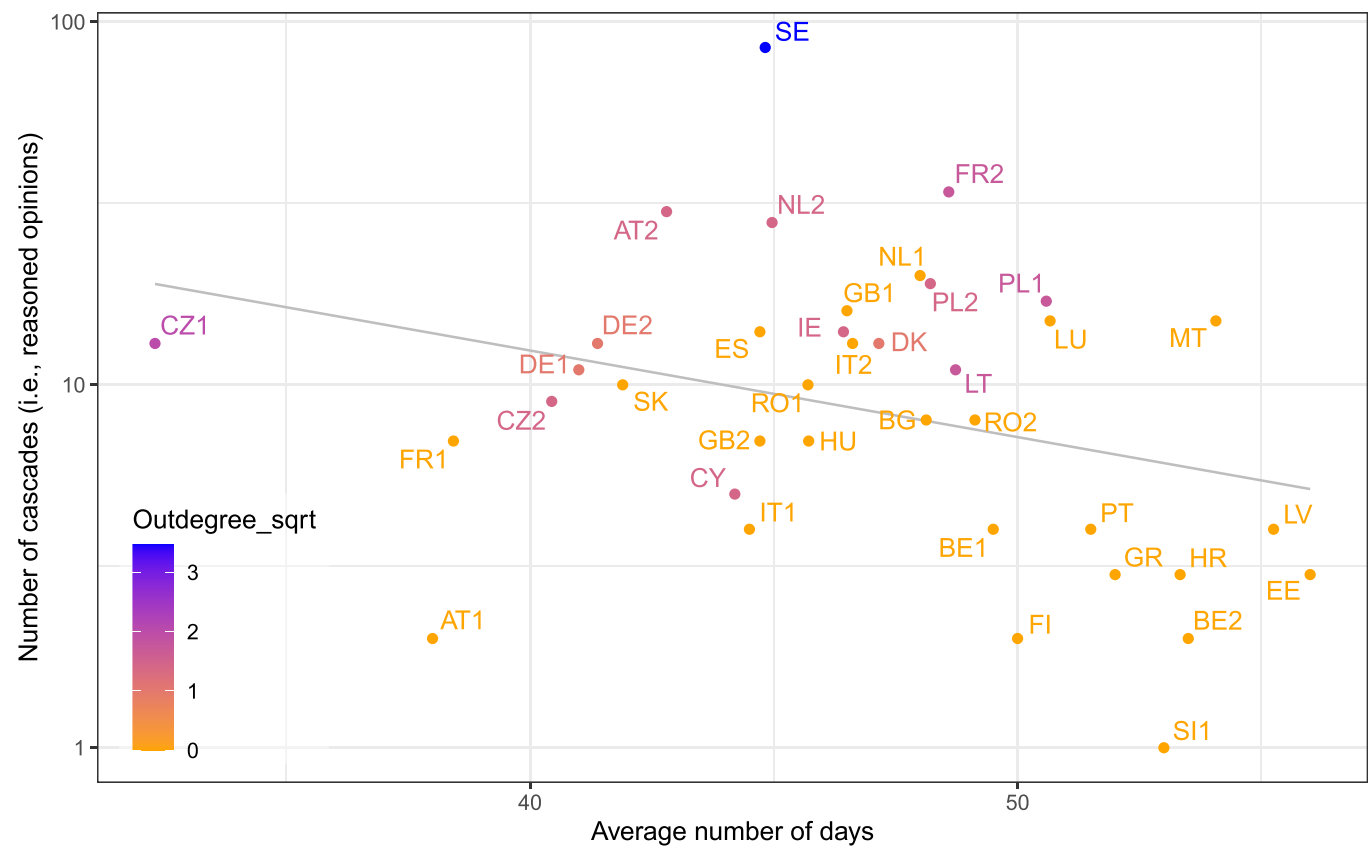

C 2021 The Authors. JCMS: Journal of Common Market Studies published by University Association for Contemporary European Studies and John Wiley \& Sons Ltd. 
much time passed on average after a legislative proposal was submitted by the Commission.

Both measures, the number and pace of submissions, can be interpreted as attributes of chambers without any relational component between chambers. We are, however, interested in the interdependent dimension of the EWS. The colour shade of the points in Figure 2 indicates to what extent chambers served as sources of diffusion - that is, opinion leaders - in the estimated diffusion network (as measured by the square-roottransformed number of outgoing ties, also known as outdegree centrality). All three characteristics - quantity, pace and opinion leadership - are moderately correlated with each other, with some outliers. For example, the French Assemblée Nationale and Slovakia's parliament are relatively fast and raise a few concerns each, but they do not act as particular sources of diffusion because other chambers do not follow their lead in particularly systematic ways.

\section{Methodology: Network Inference and Diffusion Pathways}

The method we use to infer the diffusion network that structures the observed cascades is the NETINF algorithm (Gomez-Rodriguez et al., 2012). It was introduced to the field of political science by Desmarais et al. (2015), who inferred the likely diffusion pathways between American states over many different policies, given the states' adoption times of these policies. NETINF assumes that an unobserved, latent, stable diffusion network between the nodes (here: parliaments) generates the observed cascades of adoptions (here: recorded subsidiarity concerns and their timing for the different legislative proposals). It infers this diffusion network by considering the exponentially decayed waiting times between the different actions on each sequence as an indicator of likely pathways of diffusion. We employ the R software implementation of the method in the NetworkInference package by Linder and Desmarais (2019).

The NETINF approach is based on three steps (following the exposition in Gomez-Rodriguez et al., 2012): First, it defines the probability of one node to transmit information to another node on a specific cascade as a function of the exponentially decayed waiting time that passes between any two actions on the cascade. The probability that node A 'infected' node B is relatively high if they both are active in close temporal succession and relatively low if a lot of time has passed between their actions.

Second, it defines the probability to observe a specific cascade, namely a specific diffusion sequence, or tree pattern. For each cascade, several plausible trees can be constructed that are compatible with the observed timings. The probability of any specific tree is the product of the dyadic infection probabilities in the cascade from the first step.

Third, it defines the probability of observing the cascade given the diffusion network. This is the sum of the probabilities of the different tree candidates per cascade from the second step. The product of these probabilities forms the likelihood function for observing the whole set of cascades.

We illustrate the basic procedure with an example. Take the Romanian Chamber of Deputies. As Figure 2 indicates, they submitted ten reasoned opinions. In the data supplied to the NETINF algorithm, the Romanian parliament is part of 35 activities as a potential receiver, that is, in these ten policy proposals of the Commission where they issued an opinion, 35 times another chamber issued an opinion earlier. In six out of ten 
proposals, this was the case for the Czech Chamber of Deputies and four times for the Swedish parliament. Then, the Dutch Tweede Kamer and Slovakia followed with three earlier opinions (and 14 different other chambers with fewer than three earlier opinions). This makes the chambers of the Czech Republic and Sweden strong potential sources for Romania because each could be used to explain around half of Romania's opinions. Indeed, it turns out that NETINF adds exactly these two ties to the diffusion network and drops the other ones, as our results later in Figure 4 show.

The estimation is conducted using a greedy algorithm, which starts with an empty diffusion network and subsequently adds ties that have the highest contribution to the loglikelihood, with decreasing contribution to the goodness of fit of the model. The user can specify a cut-off value for adding ties to the diffusion network.

In our application, we set the cut-off threshold to 40 ties, for three reasons: (a) this includes all ties that make a major contribution to the model fit (as per the marginal improvement); (b) this number of ties is still interpretable in network diagrams; and (c) this choice includes all diffusion ties that have $p$-values lower than 0.05 , and very few between 0.05 and 0.10 , according to the Vuong test implemented in the NetworkInference package (Linder and Desmarais, 2019). These choices are depicted in Figure 3, which plots the cut-off value as a grey vertical bar.

Finally, after inferring the diffusion network using NETINF, we used spinglass community detection (Reichardt and Bornholdt, 2006), a graph clustering technique

Figure 3: Cut-off Value, Improvement in the Log Likelihood per Additional Tie, and $p$-Values for Each Tie According to the Vuong Test, for the First 170 Ties. The Same Cut-Off Value of 40 Ties Was Used for the Analysis Presented in the Main Text and an Outlier-Corrected Diffusion Network without the Swedish Parliament, which Can Be Found in Online Appendix 4. [Colour figure can be viewed at wileyonlinelibrary.com]

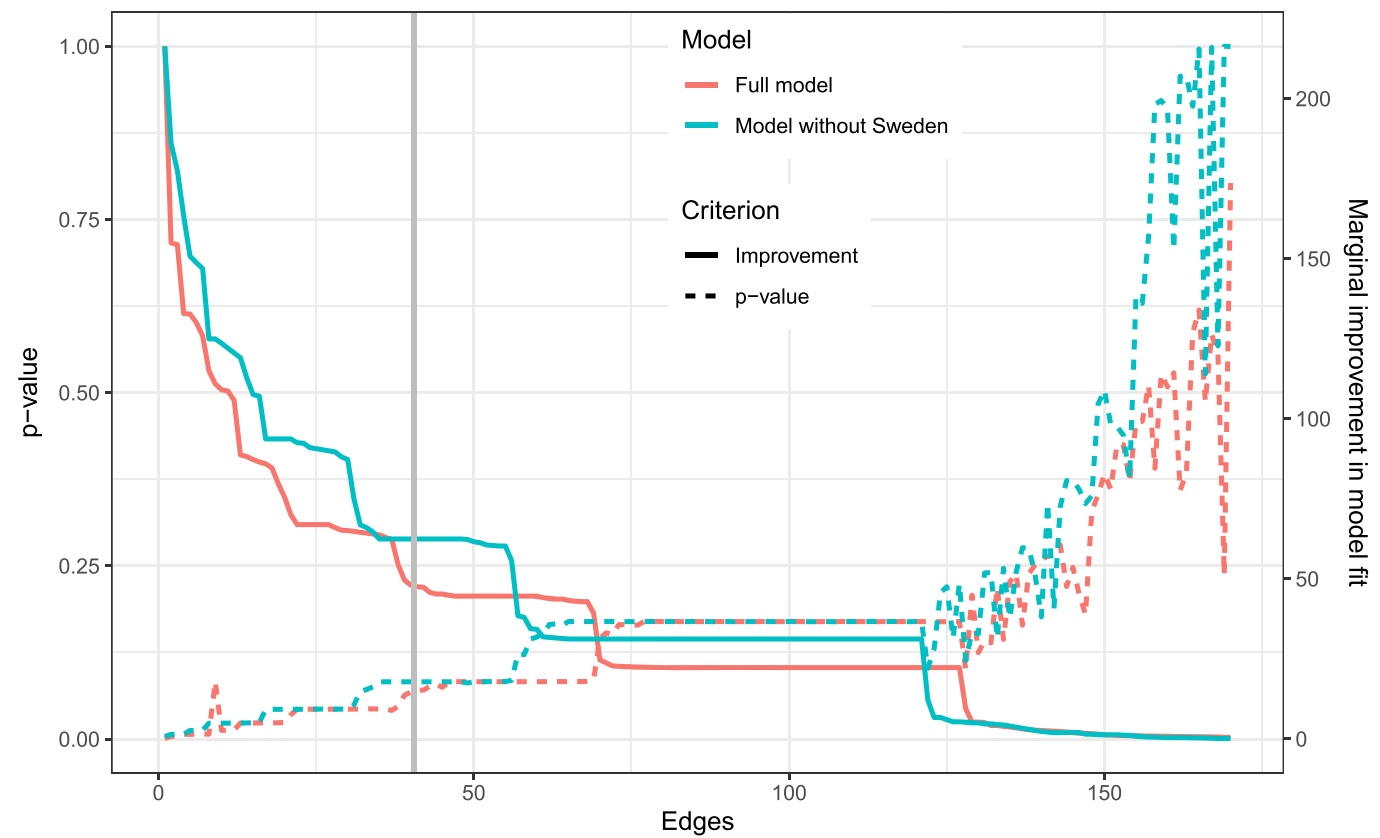

C 2021 The Authors. JCMS: Journal of Common Market Studies published by University Association for Contemporary European Studies and John Wiley \& Sons Ltd. 
implemented in the igraph R package (Csardi and Nepusz, 2006), in order to identify blocks of parliaments that were connected to each other but were sparsely connected to the rest of the network. Spinglass community detection was chosen due to its ability to produce moderately-sized communities in directed networks.

\section{Descriptive Results: Diffusion Pathways between National Parliaments}

The inferred diffusion network is shown in Figure 4. Hyperplanes indicate cluster membership. Red ties represent ties that bridge clusters. Chambers that have no diffusion ties as identified by NETINF are omitted from Figure 4 . For the 40 most influential diffusion ties, we end up with 28 chambers, including 20 lower chambers and 8 upper chambers. We will first focus on cluster memberships and then on the roles of individual nodes and ties in our interpretation.

The inferred network reveals a clear separation between Eastern European and Baltic countries on the one hand and Western and Southern European parliaments on the other hand, with the Scandinavian countries Denmark and Sweden taking a bridging position.

Figure 4: Inferred Diffusion Network with Communities. Nodes with Suffix '1' and '2' Denote First and Second Chambers, Respectively. A Version of this Diffusion Network without the Swedish Parliament Can Be Found in Online Appendix 4. [Colour figure can be viewed at wileyonlinelibrary.com]

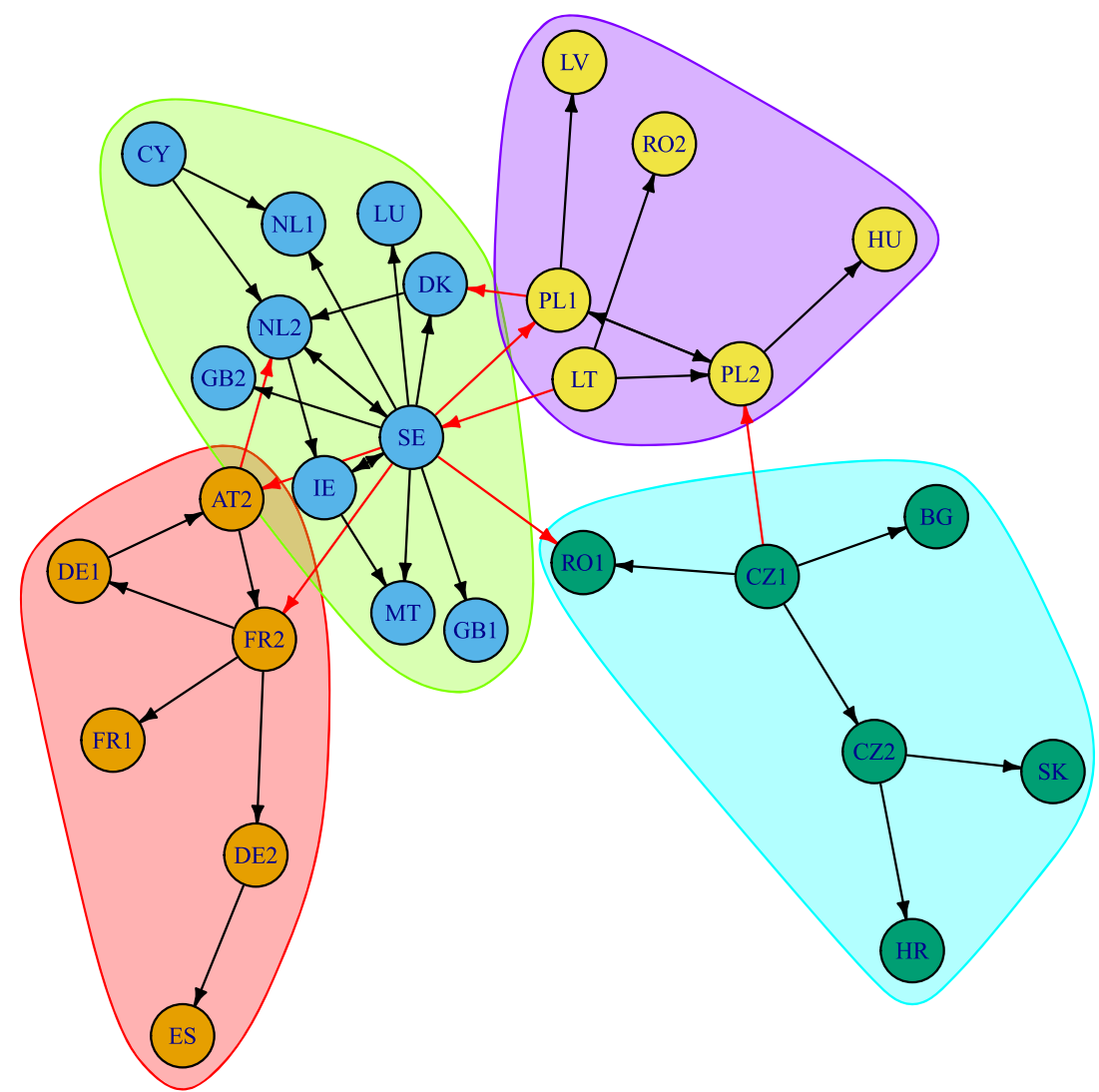

(c) 2021 The Authors. JCMS: Journal of Common Market Studies published by University Association for Contemporary European Studies and John Wiley \& Sons Ltd. 
As expected, the Swedish parliament occupies the most central role due to its sheer volume of activity.

The community detection algorithm finds four clusters based on the 40 diffusion ties identified by NETINF. Two of these (purple and turquoise) are comprised of Central and Eastern European as well as Baltic countries that joined after 2004. The third (green) cluster is the largest and most central one, with many bridging positions between clusters. It also contains the most heterogeneous group of national chambers, encompassing the BeNeLux chambers, the complete Northern enlargement cohort, the small states Cyprus and Malta as well as Sweden at the centre. The fourth cluster (red) is comprised of both French and German chambers as well as the Austrian Federal Council. Member States from the Southern enlargement cohort are only included through the Spanish Cortes Generales in this cluster.

If successful yellow cards are a function of the mobilising potential of individual chambers, which chambers can maximize the prospects of successful collective action? If we focus descriptively on the chambers that are the sender of many diffusion pathways (the outdegree centrality), we can see that Sweden is the dominant chamber with 11 outgoing ties (with four links to chambers of other clusters). The next four chambers on this scale could be interpreted as relative opinion leaders within the respective clusters, with the Czech House of Representatives (4 outgoing ties), the French Senate (3), the Polish Sejm (3), and the Seimas of the Republic of Lithuania (3).

A deeper look into case study evidence suggests several potential driving factors for the outgoing ties. The Swedish parliament (a) has a very good administrative routine in writing opinions and (b) has a different role conception of the Early Warning System, interpreting it as a form of governmental control and a form of European policy making, relative to the other chambers (Hegeland, 2015). The Czech Chamber of Deputies is described as a parliament that has one of the best accesses to governmental information sources - one senior member of the parliamentary administration described this access explicitly as "better than the Swedish Riksdag" (Hrabálek and Strelkov, 2015: 499). This access together with the increased speed of delivery seems to make the Czech first chamber an influential early adopter of subsidiarity concerns. In contrast, the French Sénat has substantially reorganised its internal procedures to be faster in the subsidiarity process (Thomas and Tacea, 2015). First, the Sénat has a working group on subsidiarity that is composed of only one representative per party group, which accelerates the scrutiny process. Second, the group leaves aside all content-related issues of a draft (the political component) and comments only on matters of subsidiarity (the legal component). This might lead to an additional acceleration of the process, but furthermore, once this non-political emphasis of the Sénat is known amongst other chambers, it could be a strong signal that a proposal really is critical on the subsidiarity dimension and should be scrutinised further.

One of the potential pitfalls of the NETINF algorithm described above is that the temporal distances between two opinions from different chambers could be too small to be interpreted as a reaction or influence. If we deleted the pathways that were on average smaller than seven days, two clusters would stay completely unchanged, namely the red and the turquoise communities. ${ }^{3}$ In the central green cluster, Sweden initiates five paths that could be contested on the grounds of temporal proximity (to NL1, RO1, IE,

\footnotetext{
${ }^{3}$ An overview about the temporal distribution of all 40 ties can be found in Online Appendix 2.

C 2021 The Authors. JCMS: Journal of Common Market Studies published by University Association for Contemporary European Studies and John Wiley \& Sons Ltd.
} 
FR2, DK). Additionally, both of the Irish and Cypriote paths are shorter than one week. The same holds for all three Lithuanian outgoing ties. Taken together, this robustness check highlights a few potentially implausible ties (for example, why should Cyprus influence both Dutch chambers?) while generally supporting the results and overall network structure.

\section{Statistical Results: Understanding the Inferred Network}

Most EWS studies examine the influence of chamber or Member State attributes on the probability of opinion formulation. It seems straightforward to apply this explanatory approach also to explaining diffusion pathways. However, since we change the perspective from a pure variable-based approach to a relational one, additional dyadic explanations should be incorporated in the explanation of whose opinions diffuse to whom. The network likely arises from a variety of Member States' and chambers' attributes and their relationship to each other, drawing on spatial, economic, political, and cultural factors. We will present such an analysis below, but also emphasise its exploratory character because it constitutes theory building as much as theory testing.

In this analysis, we evaluate the structure of the inferred network through the lens of extant theoretical expectations about the identities of leaders and followers in European politics. The analysis tests if an attribute of a chamber or a Member State can predict network ties. These attributes enter the model in two ways: as an attribute of a chamber (for example, chambers with a higher capacity are more likely to be diffusion sources or diffusion targets, respectively) and as a distance or similarity between two chambers (for example, chambers from the same enlargement round have a higher probability of a diffusion relation). The binary dependent variable indicates whether there is an inferred diffusion tie between a sender and receiver chamber. The results will be substantiated through qualitative references to the respective clusters of Figure 4.

We estimated an additive and multiplicative effects network (AMEN) model (Hoff, 2005, 2020) as implemented in the amen package (Hoff, 2015; Hoff et al., 2020), an extension of a generalised linear regression model with a logit link function by a bilinear latent space component (Hoff, 2005) and random effects for senders, receivers, and dyads (Hoff, 2020). We chose this model over its alternatives because our theoretical specification does not contain any explicit statements on the endogenous dependence to be expected between observations and it is easier to estimate in this situation since all dependencies are simply absorbed into the (bilinear) latent space component and the random effects (Cranmer et al., 2017). The results are reported in Table 1. Online Appendix 3 contains details on model specification and multiple imputation.

For an exploration of the potential driving factors of cluster formation, we started with variables that had shown a stable effect on opinion behaviour in previous studies, excluding factors that varied over time (Gattermann and Hefftler, 2015; Malang et al., 2019) because the inferred diffusion pathways vary only cross-sectionally. A description of all variables can be found in Online Appendix 3.

The first set of factors we tested for association with the inferred diffusion network revolves around geography and transnational attachment. Most diffusion studies and qualitative EWS studies assume that the location of a country will have an effect via contiguity. Chambers will look at neighbouring parliaments as a source of information on which 
Table 1: Regression of Inferred Network Ties on Monadic and Dyadic Covariates

\begin{tabular}{|c|c|c|c|c|}
\hline & Coef & $S E$ & $z$-val & $p$-val \\
\hline (Intercept) & -6.63 & 3.27 & -2.03 & 0.04 \\
\hline \multicolumn{5}{|l|}{ Geography, transnational attachment, and enlargement round } \\
\hline Sender and receiver are geographically contiguous & 0.27 & 0.45 & 0.60 & 0.55 \\
\hline Sender and receiver are in the same country & 2.24 & 1.02 & 2.20 & 0.03 \\
\hline Transnational attachment between sender and receiver & 0.05 & 0.03 & 1.41 & 0.16 \\
\hline Sender's enlargement round (from 1 to 8 ) & 0.09 & 0.25 & 0.36 & 0.72 \\
\hline Receiver's enlargement round (from 1 to 8 ) & 0.01 & 0.16 & 0.09 & 0.93 \\
\hline Sender and receiver joined the EU in the same enlargement round & -0.29 & 0.42 & -0.69 & 0.49 \\
\hline \multicolumn{5}{|l|}{ Chambers' ability to act in the EWS } \\
\hline Sender's power & 10.22 & 31.14 & 0.33 & 0.74 \\
\hline Receiver's power & -11.20 & 20.92 & -0.54 & 0.59 \\
\hline Absolute difference between sender's and receiver's power & -17.94 & 13.16 & -1.36 & 0.17 \\
\hline Sender's power is smaller than receiver's power & -0.09 & 0.52 & -0.18 & 0.86 \\
\hline Sender's capacity & -0.31 & 1.50 & -0.21 & 0.83 \\
\hline Receiver's capacity & 0.79 & 0.97 & 0.82 & 0.41 \\
\hline Absolute difference between sender's and receiver's capacity & 0.38 & 0.70 & 0.55 & 0.58 \\
\hline Sender's OPAL score & 4.84 & 3.09 & 1.56 & 0.12 \\
\hline Receiver's OPAL score & 0.26 & 1.90 & 0.13 & 0.89 \\
\hline Absolute difference between sender and receiver on OPAL score & 2.85 & 1.59 & 1.79 & 0.07 \\
\hline \multicolumn{5}{|l|}{ Budget } \\
\hline Sender's budget in billion euro & 0.14 & 0.10 & 1.43 & 0.15 \\
\hline Receiver's budget in billion euro & 0.09 & 0.06 & 1.47 & 0.14 \\
\hline Sender and receiver are both net recipients & 2.09 & 0.89 & 2.36 & 0.02 \\
\hline Sender and receiver are both net contributors & 0.07 & 0.74 & 0.09 & 0.93 \\
\hline \multicolumn{5}{|l|}{ Public mood } \\
\hline Sender's euroscepticism & 0.01 & 0.06 & 0.10 & 0.92 \\
\hline Receiver's euroscepticism & -0.05 & 0.04 & -1.23 & 0.22 \\
\hline Absolute difference between sender's and receiver's euroscepticism & 0.04 & 0.04 & 1.01 & 0.31 \\
\hline \multicolumn{5}{|l|}{ Random effects } \\
\hline Random effect for senders: within-row covariance & 1.83 & 3.27 & 0.56 & 0.58 \\
\hline Random effect for receivers: within-column covariance & 0.32 & 0.24 & 1.33 & 0.18 \\
\hline Random effect for dyads: sender-receiver covariance & 0.20 & 0.43 & 0.46 & 0.64 \\
\hline Within-dyad correlation (rho) & -0.01 & 0.37 & -0.04 & 0.97 \\
\hline Residual variance across dyads & 1.00 & 0.00 & & 0.00 \\
\hline True positives (mean) & 17.50 & & & \\
\hline False positives (mean) & 0.00 & & & \\
\hline True negatives (mean) & 716.00 & & & \\
\hline False negatives (mean) & 22.50 & & & \\
\hline
\end{tabular}

proposals to scrutinise, hence a contiguous relationship between two chambers should increase the likelihood of a diffusion tie. We included a factor that controlled whether chambers were within the same country to account for the possibility that reasoned opinions diffused among them at higher rates. Relatedly, one could view enlargement rounds as a more encompassing proxy for the spatial component of the EU (which is critical for the EFTA round with Austria being a non-contiguous state to Finland and Sweden). Finally, Deutschmann et al. (2018) correlate contiguity with transnational attachment between European societies. We used all four measures in our analysis. Whereas our qualitative view on the diffusion network suggested that at least three clusters with a spatial interpretation appeared (the two Central and Eastern European ones and the one with German, Spanish, 
French and an Austrian chamber), the quantitative analysis does not statistically support the claim of a spatial effect: neither direct contiguity, nor same enlargement round, nor transnational attachment can be identified as significant predictors of diffusion, given the data and model. Only if two chambers are in the same country, a relationship is significantly more likely than if they are in different countries, which makes intuitive sense.

A second set of explanatory variables intends to capture a chamber's abilities to act in the EWS. Previous studies that focused on EWS activity from a chamber's point of view explained variation in scrutiny as a function of the institutional strength of the chambers (Auel et al., 2015a) ( $^{4}$ and their internal capacity (Malang et al., 2019). We additionally included the power of a Member State as a predictor. For all three factors, one should hypothesise that stronger chambers are more likely sources within the diffusion network, that is, they start the diffusion process because they have the resources to scrutinise proposals on their own more efficiently. Related to that, one can also hypothesise that the difference in resources is crucial in the opinion process. Given the data and model, our results neither indicate that the power of a country in the EU decision-making process, nor show that the capacity of a chamber is a good predictor of diffusion ties. To the contrary, the OPAL score of institutional strength (Auel et al., 2015b) shows that the larger the difference in strength, the more likely a diffusion relation exists. Combined with the (albeit borderline non-significant) finding that stronger chambers are more likely the source of diffusion, we can assume that stronger chambers are early adopters of opinions that weaker chambers might follow.

Third, Bailer et al. (2015) found that net contributors to, and net recipients of, the European Union budget had different preferences leading to distinct governmental behaviour in the Council. These patterns are mirrored somewhat in the Early Warning System diffusion network as the two Central and Eastern European and Baltic communities are all composed of net recipients of the EU budget. The importance of the economic dimension within the EWS is corroborated by our quantitative analysis. Here, the attribute of being a net recipient is the second measure that reaches statistical significance on a tie level. This means that rather than looking for powerful states or strong chambers, parliaments align their EWS behaviour with chambers with the same economic preconditions.

Fourth, Williams (2016) showed that the public mood in terms of Euroscepticism influences the likelihood of submitting reasoned opinions. Parliaments representing more Eurosceptic citizens submit more opinions. From a relational perspective, one could either hypothesise that Eurosceptic parliaments are early adopters and trigger other chambers to scrutinise a given proposal or that a cluster of Eurosceptic parliaments form around a set of proposals they try to prevent. The first possibility should yield a sender effect for Euroscepticism, the second one a distance effect between two chambers with regard to Euroscepticism. However, there is insufficient statistical support to reject the null hypothesis that Euroscepticism does not matter in these ways for the diffusion network.

Overall, we not only find qualitative evidence that there were influential parliaments in the process of the three yellow cards that put their opinions forth early in the process, but we also find statistical associations that help to explain tie formation in the diffusion network. However, the majority of factors we tested seems irrelevant for the EWS backbone (though this might change with more data). The separation on the economic dimension between net recipients and contributing states seems to be the most consistent

\footnotetext{
${ }^{4}$ Auel et al. (2015a) do not focus on reasoned opinions but on the political dialogue. However, their arguments can be adopted for submissions of reasoned opinions.
} 
explanation. Generally, the relative compartmentalisation of the diffusion network into distinct communities with distinct identities and without much cross-cluster influence might explain the small number of yellow cards that have materialised up to now.

\section{Conclusion}

The Early Warning System was introduced to reduce the democratic deficit of the Union, giving elected national representatives an additional venue to participate in day-to-day legislative politics. The institutional structure of the EWS incentivises coordination and cooperation between national parliaments. Chambers with strong preferences against a given legislative draft have an incentive to find ways to make their peers jump on the bandwagon of expressing subsidiarity concerns. Chambers, legislators and parliamentary administrations that are overstrained by the volume of proposals to scrutinise are likely to look at other chambers' behaviour as a cue regarding which proposals might be worth scrutinising. The present contribution has inferred the backbone structure of this interdependent behaviour within the EWS and first described, and then explained, these diffusion patterns from a relational perspective.

The results show that the temporal sequence of raising subsidiarity concerns towards EU legislation divides national chambers into several clusters, with only a few chambers initiating stable diffusion patterns. At the chamber level, the Swedish parliament and the Czech House of Representatives are responsible for initiating many opinion sequences, which we interpret as a form of influence. At the subgroup level, our analysis revealed four distinct diffusion communities, two comprising of states that joined the EU after 2004, one cluster headed by Sweden that contains a rather heterogeneous group of chambers, and one cluster mainly composed of French and German chambers. Our statistical results are best interpreted in terms of the economic dimension, that is, net recipients of the EU budget raise subsidiarity concerns together.

Regarding the fundamental question if the EWS decreased the democratic deficit of the $\mathrm{EU}$, the fact that we found meaningful patterns of opinion diffusion could be interpreted as a slight increase of the representative function of the EU (via national parliaments). However, the normative added value of this new institution may be questioned if the Early Warning System basically exhibits the same interest constellations as the Council voting of the respective national governments. Combined with previous insights that the party channel is one premium way of influence among national parliaments (Malang et al., 2019), the Early Warning System could be viewed as largely ineffective because the national parliaments exhibit diffusion pathways that are largely congruent with existing institutional cleavage lines.

Two counter arguments exist to rescue the democratic value of the EWS: First, we have not looked at the content of the reasoned opinions so far. It is an unsettled debate if the EWS is mainly about the legal dimension (the concerns about subsidiarity) or a political one. Our results (especially the many non-significant factors in our analysis) still leave room for the interpretation that the EWS delivers an additional dimension to Council negotiations, namely to control the legal dimension of subsidiarity. Second, a recent study by van Gruisen and Huysmans (2020) showed that the Commission is more likely to withdraw proposals that receive reasoned opinions. Even in the absence of yellow cards, national elected representatives have a way of influencing European legislative 
proposals. Hence, our observed diffusion pathways can be interpreted as an additional layer to influence European policy making.

\section{Acknowledgments}

Thomas Malang gratefully acknowledges funding by the German Research Foundation DFG through the Emmy Noether programme, grant no. 447624982.

An earlier version of the paper was presented at the DVPW General Conference 2018. The authors would like to thank Oliver Treib and three reviewers for helpful comments.

Open access funding enabled and organized by Projekt DEAL.

Correspondence:

Thomas Malang

Department of Politics and Public Administration

University of Konstanz

P.O. Box 90, 78457, Germany

email: thomas.malang@uni-konstanz.de

Philip Leifeld

Department of Government

University of Essex

Wivenhoe Park, Colchester, CO4 3SQ, United Kingdom

email: philip.leifeld@essex.ac.uk

\section{References}

Auel, K. and Neuhold, C. (2017) 'Multi-arena Players in the Making? Conceptualizing the Role of National Parliaments since the Lisbon Treaty'. Journal of European Public Policy, Vol. 24, No. 10, pp. 1547-61.

Auel, K., Rozenberg, O. and Tacea, A. (2015a) 'To Scrutinise or Not To Scrutinise? Explaining Variation in EU-Related Activities in National Parliaments'. West European Politics, Vol. 38, No. 2, pp. 282-304.

Auel, K., Rozenberg, O. and Tacea, A. (2015b) 'Fighting Back? And, If So, How? Measuring Parliamentary Strength and Activity in EU Affairs'. In The Palgrave Handbook of National Parliaments and the European Union (London: Palgrave Macmillan), pp. 60-93.

Bailer, S., Mattila, M. and Schneider, G. (2015) 'Money Makes the EU Go Round: The Objective Foundations of Conflict in the Council of Ministers'. JCMS: Journal of Common Market Studies, Vol. 53, No. 3, pp. 437-56.

Baybeck, B., Berry, W.D. and Siegel, D.A. (2011) 'A Strategic Theory of Policy Diffusion via Intergovernmental Competition'. Journal of Politics, Vol. 73, No. 1, pp. 232-47.

Buzogány, A. (2013) 'Learning from the Best? Interparliamentary Networks and the Parliamentary Scrutiny of EU Decision-Making'. Practices of Interparliamentary Coordination in International Politics, pp. 17-32.

Cooper, I. (2012) 'A "Virtual Third Chamber" for the European Union? National Parliaments after the Treaty of Lisbon'. West European Politics, Vol. 35, No. 3, pp. 441-65.

Cooper, I. (2015) 'A Yellow Card for the Striker: National Parliaments and the Defeat of EU Legislation on the Right to Strike'. Journal of European Public Policy, Vol. 22, No. 10, pp. 1406-25.

Cooper, I. (2018) 'National Parliaments in the Democratic Politics of the EU: The Subsidiarity Early Warning Mechanism, 2009-2017'. Comparative European Politics, pp. 1-21. 
Cranmer, S.J., Leifeld, P., McClurg, S.D. and Rolfe, M. (2017) 'Navigating the Range of Statistical Tools for Inferential Network Analysis'. American Journal of Political Science, Vol. 61, No. 1, pp. 237-51.

Crum, B. and Fossum, J.E. (2009) 'The Multilevel Parliamentary Field: A Framework for Theorizing Representative Democracy in the EU'. European Political Science Review, Vol. 1, No. 2, pp. 249-71.

Csardi, G. and Nepusz, T. (2006) 'The Igraph Software Package for Complex Network Research'. InterJournal, Complex Systems, Vol. 1695, No. 5, pp. 1-9.

Desmarais, B.A., Harden, J.J. and Boehmke, F.J. (2015) 'Persistent Policy Pathways: Inferring Diffusion Networks in the American States'. American Political Science Review, Vol. 109, No. 2, pp. 392-406.

Deutschmann, E., Delhey, J., Verbalyte, M. and Aplowski, A. (2018) 'The Power of Contact: Europe as a Network of Transnational Attachment'. European Journal of Political Research, Vol. 57, No. 4, pp. 963-88.

Dias Pinheiro, B. (2016) 'The role of COSAC in the changing environment of national parliaments in the EU: an identity crisis?'. Interparliamentary Cooperation in the Composite European Constitution, Hart Publishing, Oxford, pp. 303-10.

Franzese, R.J., Jr. and Hays, J.C. (2006) 'Strategic Interaction among EU Governments in Active Labor Market Policy-Making: Subsidiarity and Policy Coordination under the European Employment Strategy'. European Union Politics, Vol. 7, No. 2, pp. 167-89.

Fromage, D. and Kreilinger, V. (2017) 'National Parliaments' Third Yellow Card and the Struggle over the Revision of the Posted Workers Directive'. European Journal of Legal Studies, Vol. 10, p. 125.

Gattermann, K. and Hefftler, C. (2015) 'Beyond Institutional Capacity: Political Motivation and Parliamentary Behaviour in the Early Warning System'. West European Politics, Vol. 38, No. 2, pp. 305-34.

Gilardi, F. (2012) 'Transnational Diffusion: Norms, Ideas, and Policies'. Handbook of International Relations, Vol. 2, pp. 453-77.

Goldoni, M. (2016) 'The Instrumental Value of Horizontal Parliamentary Cooperation: Subsidiarity Review and Political Dialogue'. In Lupo, N. and Fasone, C. (eds) Interparliamentary Cooperation in the Composite European Constitution (Oxford: Hart).

Gomez-Rodriguez, M., Leskovec, J. and Krause, A. (2012) 'Inferring Networks of Diffusion and Influence'. ACM Transactions on Knowledge Discovery from Data (TKDD), Vol. 5, No. 4, p. 21.

Graham, E.R., Shipan, C.R. and Volden, C. (2013) 'The Diffusion of Policy Diffusion Research in Political Science'. British Journal of Political Science, Vol. 43, No. 3, pp. 673-701.

van Gruisen, P. and Huysmans, M. (2020) 'The Early Warning System and Policymaking in the European Union'. European Union Politics, 1465116520923752.

Hegeland, H. (2015) 'The Swedish Parliament and EU affairs: From reluctant player to Europeanized actor'. The Palgrave Handbook of National Parliaments and the European Union. Palgrave Macmillan, London, pp. 425-41.

Hoff, P.D. (2005) 'Bilinear Mixed-Effects Models for Dyadic Data'. Journal of the American Statistical Association, Vol. 100, No. 469, pp. 286-95.

Hoff, P. D. (2015). 'Dyadic Data Analysis with AMEN'. Technical Report No. 638, Department of Statistics, University of Washington. arXiv preprint arXiv:1506.08237. Available online at: https://arxiv.org/abs/1506.08237.

Hoff, P. D. (2020). 'Additive and Multiplicative Effects Network Models'. arXiv preprint arXiv:1807.08038. Available online at: https://arxiv.org/abs/1807.08038. Last accessed 21 June 2020.

Hoff, P. D., Fosdick, B., Volfovsky, A., and He, Y. (2020). AMEN: Additive and Multiplicative Effects Models for Networks and Relational Data. R Package Version 1.3. Available online at: https://CRAN.R-project.org/package=amen. Last accessed 21 June 2020. 
Högenauer, A. (2015) 'The Dutch Parliament and EU Affairs: Decentralizing Scrutiny'. The Palgrave Handbook of National Parliaments and the European Union (London: PalgraveMacmillan), pp. 252-71.

Holzinger, K. and Knill, C. (2005) 'Causes and Conditions of Cross-national Policy Convergence'. Journal of European Public Policy, Vol. 12, No. 5, pp. 775-96.

Hrabálek, M. and Strelkov, A. (2015) 'The Czech Parliament and European Integration'. In The Palgrave Handbook of National Parliaments and the European Union (London: PalgraveMacmillan)), pp. 494-512.

Huysmans, M. (2018) 'Euroscepticism and the Early Warning System'. Journal of Common Market Studies, Vol. 57, No. 3, pp. 431-447.

Kinski, L. (2020) 'What role for national parliaments in EU governance? A view by members of parliament'. Journal of European Integration, pp. 1-22.

Linder, F., and Desmarais, B. A. (2019). NetworkInference: Inferring Latent Diffusion Networks. R package version 1.2.4. Available online at: https://cran.r-project.org/package=NetworkInference.

Malang, T., Brandenberger, L. and Leifeld, P. (2019) 'Networks and Social Influence in European Legislative Politics'. British Journal of Political Science, Vol. 49, No. 4, pp. 1475-98.

Neuhold, C. and Högenauer, A.L. (2016) 'An Information Network of officials? Dissecting the Role and Nature of the Network of Parliamentary Representatives in the European Parliament'. Journal of Legislative Studies, Vol. 22, No. 2, pp. 237-56.

Pintz, A. (2015) 'Parliamentary Collective Action under the Early Warning Mechanism'. Politique européenne, Vol. 3, pp. 84-114.

Reichardt, J. and Bornholdt, S. (2006) 'Statistical Mechanics of Community Detection'. Physical Review E, Vol. 74, No. 1, 016110.

Senninger, R. (2020) 'Institutional change in parliament through cross-border partisan emulation'. West European Politics, Vol. 43, No. 1, pp. 203-24.

Simmons, B.A., Dobbin, F. and Garrett, G. (2006) 'Introduction: The International Diffusion of Liberalism'. International Organization, Vol. 60, No. 4, pp. 781-810.

Sprungk, C. (2013) 'A New Type of Representative Democracy? Reconsidering the Role of National Parliaments in the European Union'. Journal of European Integration, Vol. 35, No. 5, pp. 547-63.

Thomas, A. and Tacea, A. (2015) 'The French Parliament and the European Union'. The Palgrave Handbook of National Parliaments and the European Union, pp. 170-90.

Victor, J.N., Montgomery, A.H. and Lubell, M. (eds) (2017) The Oxford Handbook of Political Networks (Oxford: Oxford University Press).

Walker, J.L. (1969) 'The diffusion of innovations among the American states'. American Political Science Review, Vol. 63, No. 3, pp. 880-99.

Williams, C.J. (2016) 'Issuing Reasoned Opinions: The Effect of Public Attitudes Towards the European Union on the Usage of the "Early Warning System". European Union Politics, Vol. 17, No. 3, pp. 504-21.

\section{Supporting Information}

Additional supporting information may be found online in the Supporting Information section at the end of the article.

Data S1 Supporting Information

Data S2 Supporting Information 